\title{
Common Law Partnership
}

National Cancer Institute

\section{Source}

National Cancer Institute. Common Law Partnership. NCI Thesaurus. Code C150735.

A leg al status where individuals are living in a continuous, conjug al relationship for a period of time defined by law. 